\title{
AN INTEGRATED APPROACH TO A MULTI-ATTRIBUTE DECISION PROBLEM THROUGH A CASE STUDY
}

\author{
Ashish Ganguli ${ }^{1}$, Yong Zeng ${ }^{1}$, Akif A. Bulgak ${ }^{2}$ \\ ${ }^{I}$ Concordia Institute for Information Systems Engineering \\ ${ }^{2}$ Department of Mechanical and Industrial Engineering, \\ Faculty of Engineering and Computer Science, Concordia University, \\ 1455 de Maisonneuve West, Montreal, QC H3G 1M8, Canada \\ ashi_gan@alcor.concordia.ca; zeng@ciise.concordia.ca; bulgak@vax2.concordia.ca
}

\begin{abstract}
This article presents an integrated approach to reaching a robust decision in a full-scale multi-attribute decision problem inspired from a real-word case. The Hypothetical Equivalents and In-Equivalents Method (HEIM) is first validated using the fill-scale decision problem. The major drawbacks of HEIM have been identified. In an attempt to eliminate the drawbacks of the HEIM, the Game Relative Importance Method (GRIM) is integrated into the method for a robust solution. The results obtained from the application of this integrated approach to the real-life decision problem have been presented. We conclude that the new approach presented yields good and efficient solutions with less computational time in comparison to applying only the HEIM.
\end{abstract}

\section{INTRODUCTION}

One of the initial stages in a product development process is the generation of design concepts. Once several alternative design concepts are generated, a decision has to be made to select the best alternative for manufacturing. This decision is usually based on the utility of both the customer and the producer. Multiple conflicting criteria are often involved, where some alternatives may be superior in one aspect but inferior in others (Shah et al., 2000). This type of problem is known as the Multiple Selection Criteria Problem (MSCP) or the Multiple Criteria Decision Making (MCDM) (Fernandez et al., 2005). Various approaches and tools have been developed to solve the MSCP problems. One of the approaches proposed to address the problem is the Utility Theory in which a utility function is defined for modeling the uncertain values of decision maker's preference (Hazelrigg, 1998) to provide the preference structure (Fernandez et al., 2005). However, the utility function cannot be used to formulate the problem when precise values are available. As an alternative, the Hypothetical Equivalent and In-equivalent Method (HEIM) is one of the most advanced methods recently developed. It is successful in accommodating multiple attributes and formulating the MSCP problem to find a robust solution by calculating the weights and equating the value functions but it is unable to identify 
relevant attributes (Shah et al., 2000). The number of attributes incorporated into the problem is done arbitrarily. Methods such as factor analysis (Urban and Hauser, 1993) and weighted factor analysis (Hessami and Hunter, 2002) can be used to list important attributes. However, such analysis requires extensive efforts from a group of experts to predict the positive and negative effects of each factor and making a hierarchical decomposition of those factors (Hessami and Hunter, 2002). Such a process is time consuming and expensive. A need for a quick and efficient process is hence evident. The proposed Game Relative Importance method (GRIM) takes into account the contribution of each attribute into the problem and finds such a hierarchical order. To establish an order a comparison is done based on differences in attribute level within the alternatives. In this article, an integrated approach combining HEIM and GRIM is proposed to overcome the existing problems of current methods.

\section{INTEGRATION OF HEIM AND GRIM METHODS}

HEIM method solves for robust weights by re-constraining the problem (See and Lewis, 2003). The utility function can be given as a multi-linear, multiplicative or an additive function. In the first case there is a set of attributes $Y=\left\{A_{1}, A_{2}, \ldots, A_{n}\right\}$ needed to characterize the design and the complement of $A$ is $Y^{\prime}$, where $Y$ is independent of $Y^{\prime}$. For the second case each attribute should be independent of other and so is in the third case. For this to happen, any important attribute not selected for solving the MSCP problem will independently act as an inhibitor to the design decision. Hence, the major drawbacks of HEIM are its inability to identify the significant attributes for MSCP problem (See and Lewis, 2003) as well as the absence of constraint analysis. The absence of constraint analysis may result in lengthening the problem unnecessarily or may overconstrain the problem. The general formulation for the weights is given by:

$$
\begin{gathered}
\operatorname{Min} \mathrm{F}(\mathrm{w})=\left(1-\sum_{j=1}^{n} y_{j}\right)^{2} \\
\text { s.t. } \mathrm{h}(\mathrm{x})=0 \text { and } \mathrm{g}(\mathrm{x}) \leq 0
\end{gathered}
$$

where $x$ is the attribute weight vector, $n$ is the number of attributes, $w_{j}$ is the weight of $j^{\text {th }}$ attribute, and both $h(x)$ and $g(x)$ define constraints. For example, $h(x)=0$ means that the decision maker prefers alternative $A$ and $B$ equally. This gives $V(A)$ $=V(B)$ and the inequality constraints are formed when decision maker prefer alternative $A$ over $B$, i.e. $V(A)>V(B)$ or $V(A)-V(B)-\alpha=0$, where

$$
\mathrm{V}(\mathrm{A})=\sum_{i=1}^{n} w_{\mathrm{i}} \mathrm{a}_{\mathrm{i}}
$$

$\alpha$ is the penalty function, a small positive number to get the equality. After getting a solution set $S_{n} \in\left\{S_{1}, S_{2}, \ldots, S_{n}\right\}$ for multiple set of weights, the value functions are equated:

$$
\sum_{i=1}^{n} w_{\mathrm{i}_{\mathrm{i}}} \mathrm{a}_{\mathrm{j}}=\sum_{j=1}^{n} w_{\mathrm{j}} \mathrm{a}_{\mathrm{j}}
$$


Upon rearrangement,

$$
\mathrm{V}\left(\mathrm{h}_{1}\right)=\sum_{i=1}^{n} \mathrm{~h}_{1 \mathrm{i}} \mathrm{w}_{\mathrm{i}} \text { and } \mathrm{V}(\mathrm{h} 2)=\sum_{j=}^{n} \mathrm{~h}_{1 \mathrm{j}} \mathrm{w}_{\mathrm{j}}
$$

where $h_{1}$ and $h_{2}$ are new hypothetical alternatives.

Further preference structure should be given by stating either $h_{1}>h_{2}$ or $h l<h 2$ to form $\mathrm{g}(\mathrm{x})$ and the process is repeated until a robust solution has been reached (Gurnani et al., 2003). From the complete list of the design attributes, one can often observe that while some attributes are very important, some others may not be irrelevant. The constraint analysis done in the case study, presented in section 3 , with 13 design variables out of the 42 availables, based upon 3 level $3^{13-10}$ factorial, resulted in an over constraint problem with no solution. After the constraint analysis it was observed that when $N\left(G_{i}\right) \rightarrow 10 \& N(f) \rightarrow 3$ :

$$
\mathrm{S}_{\mathrm{n}} \in\left(\mathrm{S}_{1}, \mathrm{~S}_{2}, \mathrm{~S}_{3} \ldots, \mathrm{S}_{\mathrm{m}}\right) \rightarrow \mathrm{Q}\left(\mathrm{S}_{1}, \mathrm{~S}_{2} \ldots \mathrm{S}_{\mathrm{m}}\right)
$$

where $N(f)$ is the number of factor level, $N\left(G_{i}\right)$ is the number of constraints, and $\mathrm{Q}\left(\mathrm{S}_{\mathrm{i}}\right)$ is a set of "no solution" or "solution" based on constraints rearranged by changing the preference structure. Human judgment is required for selection of the correct list of attributes, which often contains bias. A new Game Relative Importance Method (GRIM) is proposed to identify those attributes, which make significant contribution. After the decision matrix is prepared relative importance is provided on a scale of 5 to 1 . A baseline alternative is selected marking " $\mathrm{S}$ ". Alternatives if having different attribute values are marked S1, S2 and so on without an increasing or decreasing order. The game value and justified importance is calculated and the relevant attributes are hence selected based upon a preset criterion. The method will be clearer through the case study. In the GRIM, the final selected design efficiency can be represented as:

$$
\eta \oplus \mathrm{A}(i \mathrm{ijk} \ldots . . . \mathrm{n})^{n}
$$

where $\mathrm{A}\left({ }_{\mathrm{ijk} \ldots . . . n}\right)^{\mathrm{Jl}}$ is the set of last offspring attribute with the highest justified importance, and $\oplus$ is the structure.

These two techniques are integrated in our approach in order to find a robust selection. This integrated approach makes the initial relative importance change according to the game value. The effect of such change is prominent in the decisionmaking process. In the beginning, a particular attribute may seem to be unimportant for selection but its sub-attribute may have a direct impact on the final efficiency of the product depending upon its comparison with other such criteria for all the alternatives. If $\mathrm{A}_{\mathrm{i}}, \mathrm{B}_{\mathrm{i}}, \mathrm{C}_{\mathrm{i}}$ are set as different parent attributes, then for a product:

$$
A_{i j} \in\left(A_{i}\right)^{p}
$$

where $A_{i j}$ are the offspring attribute and $\left(A_{i}\right)^{P}$ is the parent attribute. Similarly the next generation of attributes $A_{i j k} \in A_{i j}$ and the last offspring attribute $A_{i j k} \ldots . . . n$ will be the set of the last offspring attribute. Any one of these sets of offspring attributes 
having a higher justified importance affects the product efficiency inspite of having a low importance of its parent attribute. GRIM identifies the number of alternatives in the decision matrix to be $n$ and $m$ being the number of alternatives with the same value for each criterion. It solves for the number of true comparisons within an attribute for all the alternatives. The game value and justified importance of the attributes are given as:

$$
\begin{gathered}
\mathrm{G}=[\{\mathrm{n}(\mathrm{n}-1) / 2\}-\{\mathrm{m}(\mathrm{m}-1) / 2\}] \\
\mathrm{JI}=\mathrm{RI}+[\mathrm{n}-\mathrm{G}]
\end{gathered}
$$

where $\mathrm{n}=$ number of alternatives, $\mathrm{m}=$ number of alternatives with same attribute value, $\mathrm{RI}=$ Initial relative importance, and $\mathrm{JI}=$ Justified importance.

\section{CASE STUDY}

An example case study is given in this section to illustrate the integrated approach. Five hypothetical aircrafts belonging to the super-light business jet category were selected for the case study: Jet Mod 04, Jet Mod 04 XR, Jet Mod 06 super-light, Jet Mod 06 XR super-light, and Jet Mod 08 midsize. These small aircrafts generally have a seating capacity between 7 and 9 and mainly used for business travel. A general specification chart is given in following subsequent tables categorized into general, performance and dimensions. A complete list of data with 42 criteria for selection was acquired to analyze the problem. A relative importance was given according to a scale from 5 to 1 , where 5 is deemed to be the highest important parameter and 1 to be the lowest one. The parent attribute sets are identified as general, performance, dimension, and rated as shown in Table 1.

\begin{tabular}{|c|c|c|c|c|c|c|c|c|c|c|c|}
\hline & \multicolumn{3}{|c|}{ General $=3$} & \multicolumn{5}{|c|}{ Performance $=5$} & \multicolumn{3}{|c|}{ Dimension $=4$} \\
\hline $\begin{array}{l}\stackrel{8}{8} \\
\stackrel{7}{E}\end{array}$ & हే & 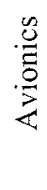 & 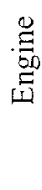 & 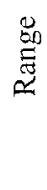 & 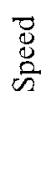 & 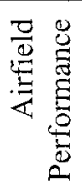 & $\frac{80}{\stackrel{\Xi}{5}}$ & $\frac{10}{0}$ & & 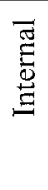 & $\begin{array}{l}\frac{5}{5} \\
\frac{5}{00} \\
\frac{0}{3} \\
3\end{array}$ \\
\hline$\underline{\Xi}$ & 2 & 5 & 4 & 5 & 4 & 5 & 4 & 4 & 4 & 5 & 5 \\
\hline
\end{tabular}

Table 1. Relative importance table

After the initial relative importance rating was given and the analysis of each offspring attribute was done and rated, the Jet Mod 04 (JM04) was selected as the baseline and marked as " $\mathrm{S}$ ". Depending on the actual attribute value of each aircraft (i.e. $\mathrm{S} 1, \mathrm{~S} 2, \ldots \mathrm{Sn}$ ), different attribute values are marked without necessarily being in an increasing or decreasing order. These $S$ values were used to find the number of games occurring within the problem. Combining equation 8 and 9 , the equation 10 was developed: 


$$
J I=I R+[n-[\{n(n-1) / 2\}-\{m(m-1) / 2\}]]
$$

The justified importance rating was given at the bottom row of each table. If one of the most important attributes having a rating of 5 in each alternative is present with a game value of zero, then its contribution to the overall problem is null since it gives no valuable input to reject its competitive alternative. Thus only the attributes with relative importance $\geq 3$ and $\mathrm{J}=5$ are selected and marked as " $5 \mathrm{~S}$ " and if $\mathrm{JI}=5$ and relative importance $\leq 3$ then it is marked as " $5 \mathrm{E}$ " and not selected.

Based on the results of general, performance (Tables 2, 3) and dimension criteria 7 parameters were selected as an input to the MSCP problem. A modified limit calculation for normalization was done to prevent absolute 0 and 1 values. The calculation is represented in equation (11). The selected attribute normalized data table or decision matrix (Table 4,5 ) is prepared showing actual data as well as the modified normalized scores according to the equation 11 . The normalized score is obtained based on the utility preference structures for each attribute. The value functions are calculated and shown in Table 6.

$$
\begin{gathered}
\text { Delta }=10 \% \text { of }(\text { Max value }- \text { Min value }) \\
\text { Lower limit }=\text { Min value }- \text { Delta } \\
\text { Upper limit }=\text { Max value }+ \text { Delta }
\end{gathered}
$$

\begin{tabular}{|c|c|c|c|c|c|c|c|c|c|c|c|c|}
\hline \multirow[t]{3}{*}{ Alt. } & \multicolumn{12}{|c|}{ General $=3$} \\
\hline & \multicolumn{2}{|c|}{ Cap. $=2$} & \multicolumn{7}{|c|}{ Avionics $=5$} & \multicolumn{3}{|c|}{ Engine $=4$} \\
\hline & $\begin{array}{l}\pi \\
3 \\
0 \\
0 \\
0\end{array}$ & $\begin{array}{l}\pi \\
\tilde{O} \\
\tilde{Z}\end{array}$ & $\frac{\pi}{I I}$ & $\underset{\sim}{\stackrel{\sim}{\sim}}$ & $\underset{\mathbb{N}}{\mathbb{N}}$ & $\underset{I}{\mathbb{I}}$ & $\begin{array}{l}n \\
n \\
n\end{array}$ & $\begin{array}{l}n \\
\text { ñ } \\
0\end{array}$ & $\stackrel{\mathbb{I}}{\mathbb{I}}$ & $\frac{\mathbb{I}}{I I}$ & $\underset{\sim}{\mathbb{I}}$ & $\underset{m}{m}$ \\
\hline JM04 & $S$ & $\mathrm{~S}$ & $\mathrm{~S}$ & $\mathrm{~S}$ & $\mathrm{~S}$ & $S$ & $\mathrm{~S}$ & $\mathrm{~S}$ & $\mathrm{~S}$ & $\mathrm{~S}$ & $\mathrm{~S}$ & $\mathrm{~S}$ \\
\hline JM04XR & $\mathrm{S}$ & $\mathrm{S}$ & $\mathrm{S}$ & $\mathrm{S}$ & $\mathrm{S}$ & $\mathrm{S}$ & $\mathrm{S}$ & $\mathrm{S}$ & $S$ & $\mathrm{~S}$ & $\mathrm{~S}$ & $\mathrm{~S}$ \\
\hline JM06 & $\mathrm{S}$ & S1 & $\mathrm{S}$ & $\mathrm{S}$ & $\mathrm{S}$ & $\mathrm{S}$ & $\mathrm{S}$ & $\mathrm{S}$ & $\mathrm{S}$ & $\mathrm{S}$ & $\mathrm{S}$ & $\mathrm{S}$ \\
\hline JM06XR & $\mathrm{S}$ & $\mathrm{SI}$ & $\overline{\mathrm{S}}$ & $\overline{\mathrm{S}}$ & $\mathrm{S}$ & $\mathrm{S}$ & $\mathrm{S} 1$ & $\mathrm{S1}$ & $\mathrm{Sl}$ & $\mathrm{S}$ & $\mathrm{S}$ & $\mathrm{S}$ \\
\hline JM08 & $\mathrm{S}$ & $S$ & $S$ & S1 & $\mathrm{S}$ & $\mathrm{S}$ & $\mathrm{S}$ & $\mathrm{S}$ & $S$ & $\mathrm{~S}$ & $\mathrm{~S} 1$ & $\mathrm{~S}$ \\
\hline JI & 1 & 3 & 0 & 2 & 0 & 0 & 4 & 4 & 4 & 0 & 3 & 0 \\
\hline
\end{tabular}

Table 2. Comparison \& Relative importance for General Criteria

Engine: $\mathrm{F} 1=$ Honeywell TFE731-20-AR, F2= Thrust, F3= Flat rating ISA +16 ${ }^{\circ} \mathrm{C}$. Avionics: $\mathrm{F} 1=$ Honeywell primus 1000,4 tube EFIS, F2 $=$ Crew advisor system, F3= Honeywell primus 660 weather radar, F4=Dual primus nav/comm. System, F5='Traffic collision avoidance system (TCAS 2000), F6=Enhanced ground proximity warning system (EGPWS) with wind shear, F7= Emergency locator transmitter (ELT). 
Table 3. Comparison and Relative importance for Performance Criteria

\begin{tabular}{|c|c|c|c|c|c|c|c|c|c|c|c|}
\hline \multirow[t]{3}{*}{ Alt. } & \multicolumn{11}{|c|}{ Performance $=5$} \\
\hline & \multirow{2}{*}{$\begin{array}{c}\text { Rng. }=5 \\
\mathbb{2} \\
\sum \\
\sum\end{array}$} & \multicolumn{3}{|c|}{ Speed $=4$} & \multicolumn{2}{|c|}{$\mathrm{AP}=5$} & \multicolumn{2}{|c|}{ Ceiling $=4$} & \multicolumn{3}{|c|}{ Noise $=4$} \\
\hline & & 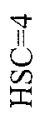 & $\stackrel{n}{\pi}$ & 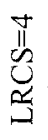 & 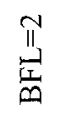 & $\stackrel{n}{\Perp 1}$ & 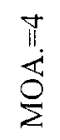 & $\mathbb{U}_{0}^{\mathbb{U}}$ & $\underbrace{\mathbb{Z}}_{0}$ & $\begin{array}{l}\text { サ } \\
\dot{0} \\
\dot{z}\end{array}$ & ${ }^{\pi_{0}}$ \\
\hline JM04 & $\mathrm{S}$ & $\mathrm{S}$ & $\mathrm{S}$ & $\mathrm{S}$ & $S$ & $\mathrm{~S}$ & $S$ & $\mathrm{~S}$ & $\mathrm{~S}$ & $\mathrm{~S}$ & $\mathrm{~S}$ \\
\hline JM04XR & $S$ & $\mathrm{~S}$ & $\mathrm{~S}$ & $\mathrm{~S}$ & S2 & $\mathrm{S}$ & $\mathrm{S}$ & $\mathrm{S} 2$ & $\mathrm{~S} 2$ & $\mathrm{~S}$ & $\mathrm{~S}$ \\
\hline JM06 & S1 & $\mathrm{S}$ & $\mathrm{S}$ & $S$ & $\mathrm{~S} 1$ & $S$ & $\mathrm{~S}$ & $\mathrm{~S} 1$ & $\mathrm{S1}$ & $\mathrm{S}$ & $\mathrm{S}$ \\
\hline JM06XR & S2 & $\mathrm{S}$ & $\mathrm{S}$ & $\mathrm{S}$ & $\mathrm{S} 2$ & $\mathrm{~S}$ & $\mathrm{~S}$ & $\mathrm{~S} 3$ & $\mathrm{~S} 2$ & $\mathrm{~S}$ & $\mathrm{~S}$ \\
\hline JM08 & S3 & $\mathrm{S}$ & $\mathrm{S}$ & $\mathrm{S}$ & S2 & $S$ & $\bar{S}$ & $\mathrm{S4}$ & $\mathrm{S3}$ & S1 & $\mathrm{S} 1$ \\
\hline $\mathrm{JI}$ & $5 \mathrm{~S}$ & 0 & 0 & 4 & $5 \mathrm{E}$ & $5 \mathrm{E}$ & 0 & $5 \mathrm{~S}$ & $5 \mathrm{~S}$ & 3 & 3 \\
\hline \multicolumn{12}{|c|}{$\begin{array}{l}\text { Rng.= Range, M.R.= Maximum Range, HSC }=\text { High speed cruise, TCS }=\text { Typical } \\
\text { cruise speed, LRCS }=\text { Long range cruise speed, } B F L=\text { Balanced field length, } \\
\mathrm{LD}=\text { Landing distance, MOA=Maximum operating altitude, } C C A=C \text { Climb to } \\
\text { cruise altitude, } T O=\text { Take off, App=Approach, } S D L=\text { Sideline }\end{array}$} \\
\hline
\end{tabular}

Table 4. Selected attribute normalized data table

\begin{tabular}{|c|c|c|c|c|c|c|c|c|}
\hline \multirow[t]{2}{*}{ Alt. } & \multicolumn{2}{|c|}{ 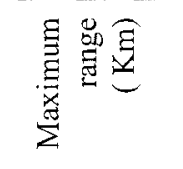 } & \multicolumn{2}{|c|}{ 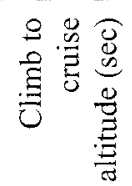 } & \multicolumn{2}{|c|}{ 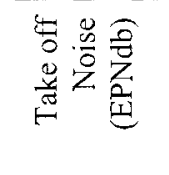 } & \multicolumn{2}{|c|}{ 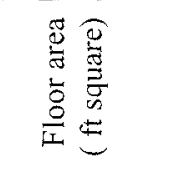 } \\
\hline & \multicolumn{2}{|c|}{ W1 } & \multicolumn{2}{|c|}{ W2 } & \multicolumn{2}{|c|}{ W3 } & \multicolumn{2}{|c|}{ W4 } \\
\hline JM04 & 3378 & 12 & 80 & 12 & 73.7 & 95 & 55.7 & 12 \\
\hline JM04XR & 3378 & 12 & 85 & 12 & 75.5 & 90 & 55.7 & 12 \\
\hline JM06 & 3763 & 30 & 82 & 30 & 74.5 & 93 & 62 & 50 \\
\hline JM06XR & 3865 & 35 & 95 & 35 & 75.5 & 93 & 62 & 50 \\
\hline JM08 & 4617 & 88 & 38 & 88 & 78.9 & 60 & 68.9 & 90 \\
\hline
\end{tabular}


Table 5. Selected attribute normalized data table

\begin{tabular}{|l|c|c|c|c|c|c|}
\hline \multirow{2}{*}{ Alt. } & \multicolumn{2}{|c|}{$\begin{array}{c}\text { Total } \\
\text { Vol. } \\
\text { (Cubic ft.) }\end{array}$} & $\begin{array}{c}\text { Basic } \\
\text { operating } \\
\text { wt.( Ib) }\end{array}$ & \multicolumn{2}{c|}{$\begin{array}{c}\text { Max. fuel } \\
\text { weight (lb) }\end{array}$} \\
\hline & \multicolumn{2}{|c|}{ W5 } & \multicolumn{2}{|c|}{ W6 } & \multicolumn{2}{|c|}{ W7 } \\
\hline JM04 & 363 & 20 & 13,718 & 12 & 5375 & 5 \\
\hline JM04XR & 363 & 20 & 13,718 & 12 & 5375 & 5 \\
\hline JM06 & 410 & 86 & 13,888 & 25 & 6062 & 25 \\
\hline JM06XR & 410 & 86 & 13,888 & 25 & 6062 & 25 \\
\hline JM08 & 453 & 95 & 14,772 & 88 & 7910 & 88 \\
\hline
\end{tabular}

A $2^{7-4}$ factorial design was used to generate hypothetical alternatives with -1 and +1 as low and high-level attribute value respectively. Stating the decision maker's preference from the hypothetical alternatives constraints g1, g2 ..g4 are formed. Re-writing equation (1) a minimization problem is formed. The objective function ensures the sum of weights being equal to unity. The minimization problem is represented is shown in equation (12).

$$
\operatorname{Min} \mathrm{F}(\mathrm{w})=\left(1-\sum_{j=1}^{n} w_{\mathrm{j}}\right)^{2}
$$

$$
\text { subject to: } \begin{aligned}
& \mathrm{g} 1=-2 \mathrm{w} 2+2 \mathrm{w} 4-2 \mathrm{w} 6+2 \mathrm{w} 7-\alpha \leq 0 \\
& \mathrm{~g} 2=-2 \mathrm{w} 3-2 \mathrm{w} 5+2 \mathrm{w} 6+2 \mathrm{w} 7-\alpha \leq 0 \\
& \mathrm{~g} 3=2 \mathrm{w} 2+2 \mathrm{w} 4-2 \mathrm{w} 6-2 \mathrm{w} 7-\alpha \leq 0 \\
& \mathrm{~g} 4=-2 \mathrm{w} 1-2 \mathrm{w} 3-2 \mathrm{w} 4-2 \mathrm{w} 6-\alpha \leq 0
\end{aligned}
$$

\begin{tabular}{|c|c|c|c|c|c|c|c|c|}
\hline Alt. & 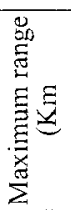 & 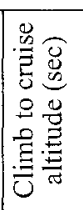 & 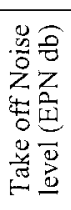 & 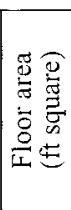 & 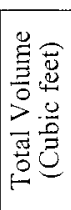 & 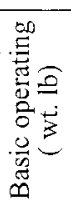 & 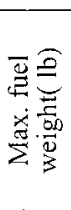 & 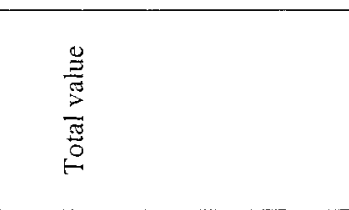 \\
\hline & W1 & W4 & W3 & W4 & W5 & W6 & W7 & \\
\hline JM04 & 12 & 80 & 95 & 12 & 20 & 12 & 5 & $\begin{array}{l}.12 \mathrm{wl}+.8 \mathrm{w} 2+.95 \mathrm{w} 3+.12 \mathrm{w} 4+ \\
20 \mathrm{w} 5+.12 \mathrm{w} 6+.05 \mathrm{w} 7\end{array}$ \\
\hline JM04XR & 12 & 85 & 90 & 12 & 20 & 12 & 5 & $\begin{array}{l}.12 w 1+.85 w 2+.9 w 3+.12 w 4+ \\
20 w 5+.12 w 6+.05 w 7\end{array}$ \\
\hline JM06 & 30 & 82 & 93 & 50 & 86 & 25 & $\overline{25}$ & $\begin{array}{l}.3 w 1+.82 w 2+.93 w 3+.5 w 4+.8 \\
6 w 5+.25 w 6+.25 w 7\end{array}$ \\
\hline JM06XR & 35 & 95 & 93 & 50 & 86 & 25 & 25 & $\begin{array}{l}.35 w 1+.95 w 2+.93 w 3+.5 w 4+ \\
86 w 5+.25 w 6+.25 w 7\end{array}$ \\
\hline JM08 & 88 & 38 & 60 & 90 & 95 & 88 & 88 & $\begin{array}{l}.88 w 1+.38 w 2+.6 w 3+.90 w 4+ \\
95 w 5+.88 w 6+.88 w 7\end{array}$ \\
\hline
\end{tabular}

Side Constraints: $0<\mathrm{w}_{\mathrm{j}}<1$

Table 6. Selected attribute value function. 
The entire two step process of first evaluating the selection criteria (Table 2,3) and dimension criteria through the GRIM process to generate the final set of attributes can be understood through the flowchart (see Figure 1). It explains the process of selecting or rejecting any particular attribute.

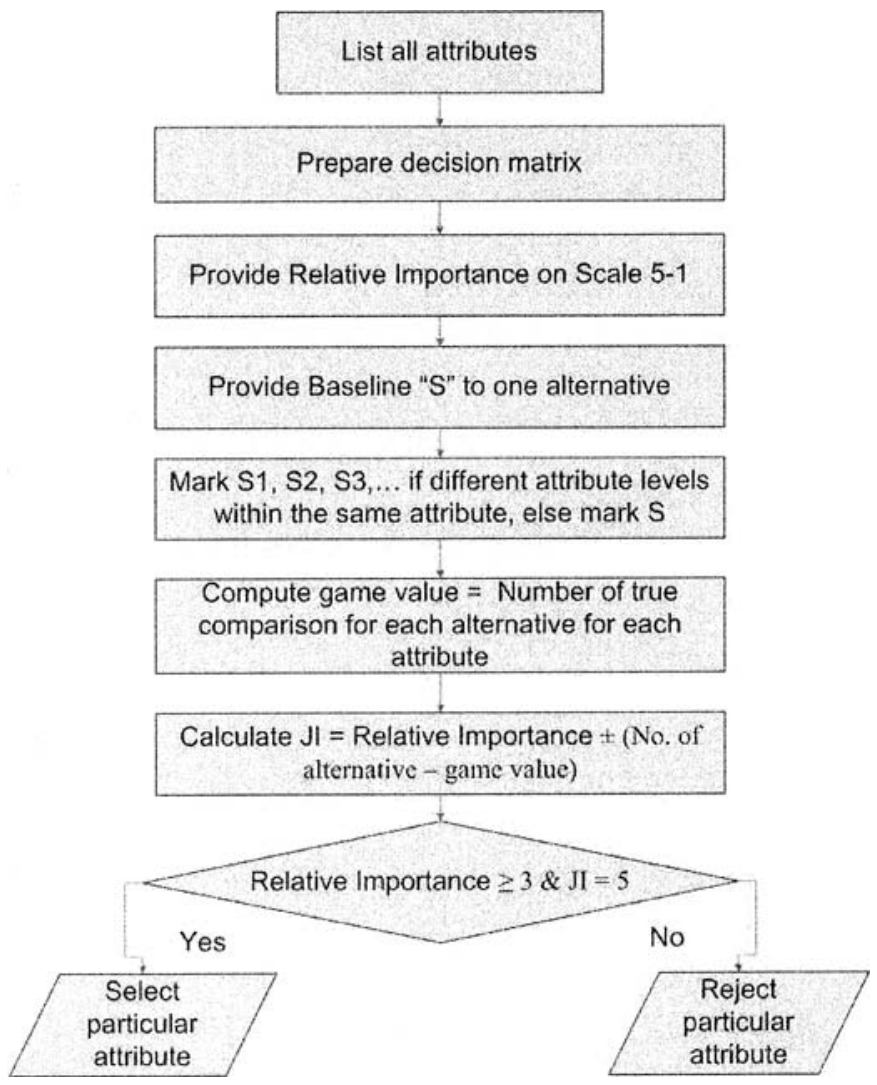

Figure 1- Flowchart of game relative importance method

This set then serves as an input to the HEIM process. A graphical illustration of the HEIM process is showed (see Figure 2). The HEIM process, as shown in figure 2 , acts on the generated final set of attributes to give our final robust solution. 


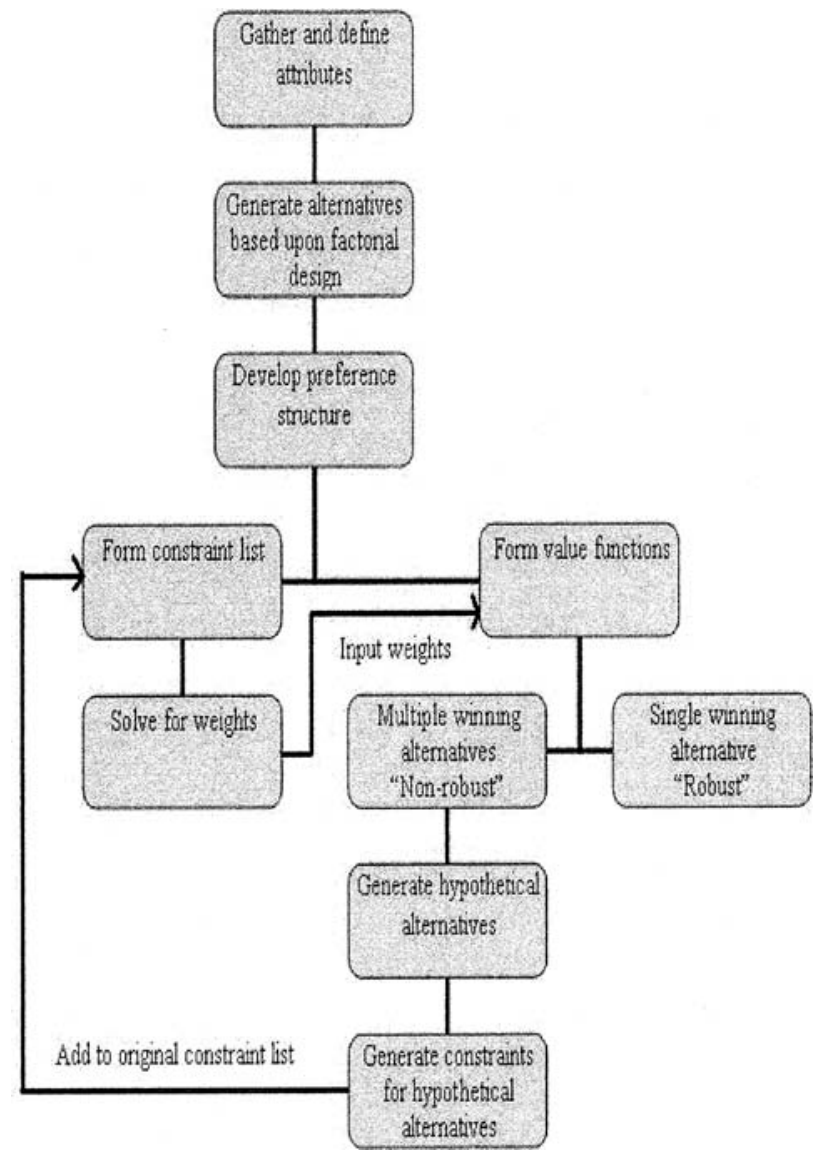

Figure 2 - Flowchart of the HEIM

A "C" program was generated to solve the minimization problem. The problem was first solved by using the HEIM alone, according to which the JM06XR is the winner. On equating the value functions and generating further hypothetical constraints two cases were reached with JM06XR as winner in case A and JM08 as winner in case B. Further, the problem was re-constrained and a robust solution was found. Multiple solutions were reached with JM08 as winner in all three cases.

\section{CONCLUSIONS AND FUTURE WORK}

The major disadvantage of the HEIM is its inability to identify the attributes which makes a significant contribution to the MSCP problem. The integrated approach taken to solve the MSCP problem with identification of maximum contributing attribute by GRIM and then solving by HEIM resulted in robust solution with 
comparatively less computation time. In this study, we additionally validated the HEIM on a full-scale problem with real time data. The robust solution indicated the Jet Mod 08 as the best choice. Our future work will focus on other applications of the approach to test its efficiency on a larger domain of decision-making problems involving multiple selection criteria. One important aspect is to effectively state the preference structures in the MSCP problem.

\section{REFERENCES}

1. Fernandez, M.G et al. "Decision support in concurrent engineering- The utility - based selection decision support problem", Concurrent Engineering: Research and Application", 2005

2. Gurnani, A., See, T.K., Lewis, K., "An approach to robust multiattribute concept selection" ASME Design technical conferences, Design Automation conference, DETC03/DAC-48707.

3. Hazelrigg, G.A.(1998). A framework for decision based engineering design, Journal of Mechanical Design, 120:653-658.

4. Hessami, A., Hunter, A., 2002, "Formalization of Weighted Factors Analysis", Knowledge-Based Systems, Volume 15, Issue 7, Pages 377-390

5. Shah, J. J., Kulkarni, S.V., Vargas-Hernandez, N., 2000, "Guidelines for Experimental Evaluation of Idea Generation Methods in Conceptual Design," Journal of Mechanical Design, 122(4) pp. 377384.

6. See, T.K., Lewis, K., "Multiattribute decision making using hypothetical equivalents" ASME Design technical conferences, Design Automation conference, DETC03/DAC-34079.

7. Urban, G. L., and Hauser J. R., 1993, Design and Marketing Of New Products, 2nd Edition, Prentice Hall, pp.1-16. 